\title{
A História na visão de Alexandre Dumas
}

\author{
Maria Lúcia Dias Mendes
}

O romantismo era a estética de uma nova sociedade que, depois de passar por modificações estruturais, como a Revolução Francesa, não acreditava mais em valores absolutos, não podia mais construir uma visão de mundo sem pensar em sua relatividade e em suas limitações históricas.

Os românticos não foram os primeiros a assumir uma atitude crítica em relação aos seus antecedentes históricos, rejeitando padrões tradicionais de cultura, buscando novas maneiras de exprimir sua própria concepção de vida. Mas nenhuma outra geração fez dessa preocupação um problema: propunham-se a pensar o significado e a raison d'être da sua própria cultura, viam-se como herdeiros e descendentes de épocas anteriores, procuravam rememorá-las, como um passado vivido." Se ansiar pelo passado poderia, por um lado, refletir uma fuga, um temor diante do presente, por outro, propiciou a conscientização histórica dos românticos, uma indagação constante do significado do presente (em todos os seus aspectos), encarado a partir de então como um fluxo contínuo, oriundo de um processo histórico ${ }^{1}$. O movimento romântico elege a História como tema: por entender-se como um movimento histórico, fruto de uma época e das mudanças que nela ocorreram, os românticos têm no olhar histórico (e, conseqüentemente, na consciência da transitoriedade das coisas) um dos seus pontos de referência.

Esse historicismo, relacionado a uma completa reorientação da cultura e da filosofia da História, provinha do reconhecimento de que os acontecimentos não têm origem em princípios formais, em idéias e entidades, em uma "lógica imanentista" da História, mas em um processo dialético, no

1 "Historicamente, o Romantismo apresenta uma dupla face. É um saudoso olhar lançado ao passado e um agoniado encontro com o presente" (Prado, Décio de Almeida. "Teatro romântico: a explosão de 1830". Em: Guinsburg, Jacob. $O$ romantismo. São Paulo: Perspectiva: 1978: 182). 
(Hauser, Arnold. História so. cial da literatura e da arte, vol. II. Ob. cit.: 827 . Hobsbawm Eric J. A era das revoluções: Europa 1789-1848. Trad. Te eza Lopes Teixeira e Mar. cos Penchel. Rio de Janeiro: Paz e Terra, 2001: 308.)

"Mello e Sousa, Antonio Can. dido. "Sob o signo do folhetim: Teixeira da Silva". Em: Forma ção da literatura brasileira, v. II (1836-1888). Belo Horizonte: Itatiaia, 1993: 118.)
"(Raimond, Michel. Le roman depuis la Révolution. Paris: Armand Colin, 1969: 21.) qual cada fator está em fluxo, sujeito a uma variação constante de significado, em uma relação de interdependência indissolúvel.*

O interesse pela História ia ao encontro do novo perfil do leitor. Após a Revolução Francesa e a instituição do ensino laico e obrigatório, há um aumento do número de leitores e uma conseqüente mudança de interesse: o público do classicismo, afeito às discussões sobre poéticas, de gosto refinado, conhecedor das novidades na arte, torna-se um público burguês, sem formação literária, em busca sobretudo de uma forma de lazer.

A História se torna, assim, um repertório mais do que atraente, tanto para o público quanto para os escritores, tomando o lugar de uma temática mais intelectualizada - como poéticas, questões sobre as universalizações românticas e outros temas impalpáveis que continuavam sendo tratados em revistas literárias. Além disso, quando usada como tema para a obra de arte - literária, pictórica ou cênica -, possibilita ao autor refletir sobre a sua época, tecendo paralelos entre o período retratado e aquele em que vive.

O romance gótico pré-romântico e o romance de aventuras são os gêneros que começam a retomar a História como pano de fundo para a narrativa (como uma couleur locale), reforçando o gosto pelo exótico, criando um atrativo a mais para enredos pouco originais - pois "o mistério lucra com o recurso a outras eras e lugares"*.

No caso do romance, se visto como "história dos costumes ou história da vida privada”, poderia passar como uma forma menor de História, mais acessível, mais profana, sem, contudo, perder o vínculo que o ligava à realidade.

Antes de Walter Scott havia um romance histórico em que se misturavam heróis imaginários e personagens históricas - como La princesse de Clèves -, mas foi ele o primeiro a ambicionar recriar épocas e mundos, tornando viva e pitoresca sua narrativa histórica. Scott conseguiu criar uma interação entre o tema histórico e sua narrativa, ao fazer uma organização dramática dos acontecimentos (isto é, estrutura o enredo do romance em partes, com exposição, crise e desenlace), criando episódios convergentes, cada qual contribuindo para fazer progredir a ação.* 
O romance histórico alcança um sucesso considerável na França da Restauração (décadas de 1820 a 1830)², com a publicação de Ivanhoé (1819), traduzido para o francês só em 1864, por Alexandre Dumas. Admirado mesmo por historiadores - Auguste Thierry dizia que o tinha como grande mestre $^{*}$ - Scott revitaliza o gênero, atraindo a atenção de alguns escritores como Alfred de Vigny, Victor Hugo, Honoré de Balzac e Prosper Mérimée, que escreveram nessa época romances históricos, respectivamente: Cinq-mars (1826), NotreDame de Paris (1831), Les Chouans (1829) e Chronique du temps de Charles IX (1829).

O sucesso do romance histórico escrito na França, entretanto, só viria mais tarde, quando Alexandre Dumas, já consagrado como dramaturgo e escritor, consegue harmonizar a História com os outros ingredientes do romance-folhetim ${ }^{3}$.

O interesse de Dumas pela História se teria iniciado em 1825. Ainda bem jovem, foi aconselhado por Lassagne (seu colega de trabalho e leitor assíduo), em uma passagem "recriada” no livro Mes mémoires, a ler alguns grandes escritores para com cada um deles aprender uma qualidade necessária ao trabalho. Entre vários nomes do teatro (Shakespeare, Corneille, Racine, Schiller, Eurípedes) e da literatura (Goethe, Cooper e outros), foi sugerido Scott, cuja capacidade de observação para o estudo dos caracteres das personagens deveria ser aprendida. Lassagne afirma também que a França "aguarda o romance histórico"; diante da resposta do jovem Dumas (“A história da França é maçante!”)", recomenda-lhe a leitura de uma série de memorialistas - e não de historiadores.

${ }^{2}$ Ainda não se pode tratar o romance histórico de Scott como um gênero específico, pois, nessa época, nem mesmo o romance era visto como tal - o que só aconteceu após as obras de Stendhal e de Balzac, que, de certa maneira, formalizaram as regras do gênero (Raimond, Michel. Le roman depuis la Révolution. Ob. cit.: 31$)$.

${ }^{3} \mathrm{O}$ romance-folhetim do século XIX é uma combinação de alguns gêneros de sucesso na época de sua criação, assim como de alguns temas e tratamentos que já tinham se tornado tradicionais. Cada autor tende mais para um ou outro ingrediente, seja temático ou estrutural. Não possui uma orientação única: reúne elementos do melodrama, do drama romântico, do romance de aventuras, do romance sentimental e do roman noir. Mas, em sua estrutura, revela a estética do romantismo: a associação do trágico e do cômico, do grotesco e do sublime, do riso e das lágrimas, o engajamento histórico e a crítica social, o drama e o pitoresco. É sobretudo através do romance-folhetim que o modelo romanesco romântico toma corpo e se difunde junto ao público.
' (Maurois, André. Les trois Dumas. Paris: Hachette, 1957: 170.) "["attend le roman historique"] ["L'histoire de la France est ennuyeuse!"] (Du. mas, Alexandre. Mes mémoi1968: 589.) 
"(Sigaux, Guilbert. "Préface". Em: Alexandre Dumas. Les trois mousquetaires. Paris: Gallimard, 1962: IX.XXV.)
Prado, Décio de Almeida. Romântico: a explo. são de 1830". Ob. cit.: 177 .)
E será pela leitura dos memorialistas que Dumas aprende História, bem mais do que em livros de síntese escritos por historiadores especializados. No caso do romance Les trois mousquetaires, a fonte principal teria sido Mémoires de M. d'Artagnan, escritas por Courtilz de Sandras e publicadas em 1700 na cidade de Colônia ${ }^{4 *}$. Outros empréstimos freqüentes são feitos das Mémoires de, entre outros, La Rochefoucault, Pierre de la Porte, Madame de La Fayette, Cardinal de Retz e Madame de Chevreuse.

Alexandre Dumas tinha experiência com os temas históricos. Seu primeiro sucesso no teatro foi Henri III et sa cour (1829), baseado no curto reinado de Henri de Valois (irmão de Marguerite de Navarre) na França. No mesmo ano, começou a publicar, no jornal La Presse, crônicas históricas, pois o tema histórico substituía no antigo folhetim o espaço dado às temáticas voltadas para leitores mais refinados intelectualmente, atendendo aos anseios do público burguês sem muita formação.

É no romance-folhetim, entretanto, que Dumas consegue um conjunto harmonioso, mesclando sua experiência como escritor de dramas românticos com alguns truques aprendidos com o melodrama e com o roman noir, e com o desenvolvimento da ação tirado do romance de aventuras e de seu interesse pela História. Nesse período, escreve, entre outros, Les trois mousquetaires (seguidos de Vingt ans après e Vicomte de Bragaleone); La reine Margot (e as continuações La dame Monsoreau e Les quarante-cinq).

Dumas tinha extrema habilidade em "formular dramaticamente idéias, pensamentos e emoções que estavam no ar" como bem define Décio de Almeida Prado -, fazendo uso de fórmulas que provinham das linguagens de sua época.* Conseguirá também se apropriar de inovações apresentadas por Scott, que utilizará de modo a aprimorar o seu estilo.

Walter Scott conseguira criar uma interação entre a personagem e o momento histórico ao qual ela pertence, transformando a História de puro décor em causadora de especificidades nos caracteres das personagens que articula. Preten-

\footnotetext{
${ }^{4}$ Segundo Claude Schopp, Dumas teria tomado emprestado da Biblioteca Municipal de Paris os quatro volumes de Mémoires de M. d'Artagnan em junho de 1843, e jamais os teria devolvido. Cf. Schopp, Claude. Le génie de le vie. Paris: Mazarine, 1997: 368.
} 
dendo criar um tableau de l'Histoire animée (algo como uma representação viva da História), mistura os conflitos internos das personagens com os conflitos históricos - reais - nos quais elas estão envolvidas. ${ }^{*}$

Apesar de não poder ser considerado o fundador do romance histórico, Scott é o primeiro a estabelecer o prestígio do gênero, tomando como assunto a História Social e tratando-a de acordo com o ponto de vista científico da elite intelectual da época. Por mais conservador que fosse em política, o seu "método sociológico" não poderia ser concebido sem as transformações que a Revolução Francesa trouxera: suas personagens têm sempre a marca da sua origem social, sem envolver entretanto qualquer compromisso, e a sua descrição das camadas inferiores é, em geral, convencional e esquemática. ${ }^{*}$

A História tende a exigir mais nuanças, mais ambigüidade do que estaria acostumado o leitor de romances-folhetins. Dumas soma, então, a essa lição recebida de Scott as artimanhas de excelente dramaturgo: dá vida aos acontecimentos ao criar personagens secundárias que agem na História, buscando segredos de alcova, mexericos de outros tempos, recriando enfim a atmosfera da época retratada. Cria uma História que, sendo mais cheia de aspectos cotidianos, consegue ser mais "real" que aquela que se lê em livros tradicionais de historiografia, exatamente como desejava o público de sua época:

Um povo que havia feito a história e visto mudanças imensas desejava penetrar na intimidade desse passado tão próximo. Mas, para interessar tanto às massas quanto aos reis e às rainhas, aos ministros e às suas favoritas, era necessário lhes revelar, sob o manto da corte, seres humanos, e, nesta tarefa, Dumas se mostrou admirável.
[...] Un peuple qui avait fait de l'histoire, et vu d'immenses changements, souhaitait pénétrer dans l'intimité de ce passé si proche. Mais pour intéresser les foules à des rois et à des reines, à des ministres et à ses favorites, il fallait leur révéler, sous les manteaux de cour, des êtres humains, en quoi Dumas pouvait se montrer admirable. ${ }^{* 6}$
"(Raimond, Michel. Le roman depuis la Révolution. Ob. cit.: 20.)

"(Lukács, George. "Walter Scott and the Historical Novel". Em: International Literature, $n^{\circ} 12,1938: 12$; Walter Scottcitado por Arnold Hauser. História social da literatura e da arte, vol.II. Ob. cit.: 869.)

\footnotetext{
${ }^{5}$ Acreditamos que essa afirmação não poderia ser feita em relação a Dumas (e nem mesmo a Victor Hugo), pois a multidão é uma personagem importante na reconstituição das cenas de seus romances.

${ }^{6}$ Dumas, em Lettre à Mery, de 25 de janeiro de 1863, demonstra consciência das transformações que a sua geração testemunhou: "Nós vimos cair tronos, repúblicas e até mesmo crenças" ["Nous avons vu tomber trônes, républiques, croyances même".] Cf. Schopp, Claude e Frémy, Dominique. "Quid de Dumas". Em: Dumas, Alexandre. Mes mémoires. Ob. cit.: 1223.
} 
"(Dumas, Alexandre. Mesmé moires, vol. II. Ob. cit.: 918.

Mais tarde, em suas memórias, Dumas comentaria a leitura que havia feito de Scott, ressaltando as diferenças entre seu estilo e o do escocês:

As qualidades de Walter Scott não são exatamente qualidades dramáticas; admirável na descrição dos modos, dos costumes e caracteres, Walter Scott é completamente inábil para dar vida às paixões. Com costumes e caracteres, podem-se fazer comédias, contudo são necessárias paixões para criar os dramas. [...] entretanto, meu trabalho com Scott não foi inútil, apesar de infrutífero; só se conhece a estrutura de um homem quando se examina cadáveres; só se conhece o gênio de um autor analisando sua obra. A análise de Walter Scott me fez compreender o romance sob um ponto de vista diferente do que encaramos em nosso país. A mesma fidelidade na descrição dos costumes e dos caracteres, com um diálogo mais vivo e com paixões mais reais, parece-me ser o que nos convém.
Les qualités de Walter Scott ne sont point des qualités dramatiques; admirable dans la peinture des moeurs, des costumes et des caractères, Walter Scott est complètement inhabile à peindre les passions. Avec des moeurs et des caractères, on peut faire des commédies; mais il faut des passions pour faire des drames. [...] Mais mon travail sur Scott ne m'avait été inutile, tout infructueux qu'il était resté; on ne connaît la structure de l'homme qu'en ouvrant des cadavres; on ne connaît le génie d'un auteur qu'en l'analysant. L'analyse de Walter Scott m'avait fait comprendre le roman sous un autre point de vue qu'on n'envisageait chez nous. Une même fidélité de moeurs, de costumes et des caractères, avec un dialogue plus vif et des passions plus réelles, me paraissait être ce qui nous convenait."

Ao que parece, Dumas, após fazer a “análise” das narrativas de Scott, percebe que, apesar de possuir algumas qualidades desejáveis, tais como oferecer uma nova visão do romance e uma maneira interessante de fazer a caracterização dos costumes da época retratada, não conseguia em suas intrigas alcançar a dramaticidade esperada. É interessante notar que Dumas, ao criticar Scott, articula o que seria a sua própria técnica de romance histórico: buscar a fidelidade de representação dos hábitos, costumes e do espírito da época tratada e usar diálogos mais ágeis e paixões mais reais. Uma fala do personagem Eugène (o poeta romântico) no drama romântico Antony pode servir para ilustrar a perspectiva dumasiana de uso da História como recurso dramático: 
A História nos lega os fatos, que nos pertencem por direito de herança, são incontestáveis e estão à disposição do poeta: ele exuma os homens de antigamente, revesteos com seus costumes, reascende as suas paixões, que ele aumenta ou diminui tendo em vista o ponto a que deseja levar o drama.
L'Histoire nous lègue des faits, ils nous appartiennent par droit d'héritage, ils sont incontestables, ils sont au poète: il exhume les hommes d'autrefois, les revêt de leurs costumes, les agite de leurs passions, qu'il augmente ou diminue selon le point où il veut porter le dramatique.*
"(Dumas, Alexandre. Antony. Em: Théâtre complet, tII. Pa. ris: Minard, 1975: 274.)

O que o francês talvez não perceba é que, de certo modo, as motivações do escocês eram diferentes das suas. Walter Scott se inseria em um movimento que, desde o fim do século XVIII, provocava, em alguns países europeus, um forte interesse em pesquisar tradições populares e recriá-las. Assim, antes de escrever Ivanhoé, seu romance histórico por excelência, pesquisara baladas e tradições da Escócia, no intuito de contribuir para com a preservação da história de sua terra natal, que estava se dissolvendo e se misturando à da Inglaterra."

Dumas, por mais que dissesse que "nossa pretensão escrevendo romances históricos não é somente divertir uma classe de nossos leitores que sabe, mas instruir uma outra que não sabe", ficava muito distante do nacionalismo que movia o "bardo escocês". Escrevia na França, em uma nação - conceito que a Revolução Francesa criara e difundira pelo mundo - embalada por uma segunda revolução vitoriosa (a de 1830), em que a arte e a política se uniram em busca de uma arte "para o bem da humanidade". Na década de 1840, já não era mais uma questão de afirmação ou legitimação política e artística (como talvez tivesse sido nos primeiros tempos do romantismo, com as primeiras obras do drama romântico), mas sim de um romantismo mais bem comportado, "um romantismo de salão elegante"*.

Além disso, a sua visão do romance histórico - a necessidade de paixão nos dramas - só era possível para alguém que se norteasse pelos princípios do drama romântico, que fosse hábil o bastante com o tratamento das personagens e dos diálogos. Entretanto, apesar da consciência, digamos assim, da limitação da obra de Scott, muitos defendem que Dumas teria sido "pego pela mesma armadilha", ao criar, muitas vezes, personagens sem profundidade, extremamente servis aos seus enredos cheios de peripécias. 
"(Ariès, Philippe. Otempo da História. Ob. cit.: 212.)
"(Duby, Georges. "Un précur. seur, entretien avec Gérard Khoury". Em: Europe; Revue Littéraire Mensuelle. Paris: Les Éditeurs Français Réu nis, 1998, mai: 36.44.)

"appris à la France autant d'Histoire qu'aucun histo rien", pois "I'amusement, chez nous, n'aété qu'un mas que à 'instruction". (Dumas citado por Schopp, Claude Dumas". Ob. cit.: 1237.)
Quanto à historiografia de sua época, Dumas admirava o trabalho de Jules Michelet (que também era seu admirador), cuja narrativa apaixonada e o desejo de ressuscitar o passado eram movidos pelo mesmo "desenraizamento" que poetas e romancistas pediam à ficção e à ficção histórica. "Michelet possuía uma técnica interessante de historiografia: procurava alimentar-se de fontes e documentos de época - foi chefe da divisão histórica dos Arquivos Nacionais de Paris por muitos anos -, ao mesmo tempo em que reservava um papel importante nas suas narrativas para o povo, massa de pessoas que até então havia sido mantida longe da cena histórica ${ }^{7}$. Pretendia fazer reviver o passado, acreditando que o historiador deveria produzir uma síntese entre o fato histórico e a sua vivência, sempre movido por sua sensibilidade.

Por mais que Michelet não gostasse de romances históricos, seus procedimentos podem facilmente ser tomados pelos mesmos usados por escritores de ficção. Sua escritura estava completamente envolvida pelo espírito romântico: se, por um lado, vemos sua extrema capacidade de trabalhar os arquivos e fontes que abriram a História para outros domínios acreditava em uma História que abrangesse a filosofia, artes e outros ramos de conhecimento - por outro, deformava essas fontes, fazendo uma leitura às vezes engajada, às vezes sensibilizada com os fatos de que tratava. O papel do historiador, para ele, era mostrar que o passado tem um sentido e que é necessário influenciar o futuro.*

Alexandre Dumas não possui nenhum projeto historiográfico bem definido, entretanto diz que, ao escrever, almeja dois objetivos: instruir e divertir. Após ter escrito vários romances históricos, diz ter a pretensão de ter "ensinado à França [...] mais História do que qualquer historiador [pois] a diversão para nós foi apenas uma máscara para a instrução"*. Apesar disso, cria antes de tudo um espetáculo: corta a História em cenas e diálogos, fazendo uma montagem. Tudo,

${ }^{7}$ Não podemos deixar de comentar que em 1846, Michelet publica um livro intitulado Le peuple. Dedicado a Edgard Quinet, o livro é uma reflexão sobre o povo e uma espécie de "profissão de fé" do autor na capacidade deste de fundar uma "fraternidade social". Michelet não escapa do socialismo reinante entre os intelectuais de sua época - apesar de criticar o tipo de discurso de Victor Hugo, por ser muito teórico e apresentar uma visão estereotipada do povo. Os ares do romantismo ainda podem ser notados nas sonoridades das palavras, no ritmo das frases, na eloqüência e no uso freqüente de imagens. 
ou quase tudo em sua narrativa, está na ação. A reflexão é breve $^{8}$ e as descrições conferem um pouco de movimento e realidade às tomadas históricas, pois todos os recursos se desdobram para atender às peripécias do enredo.

Uma boa maneira de compreender a técnica romanesca de Dumas é comparar o texto do qual partiu a idéia e o romancefolhetim criado por ele, como, por exemplo, o folhetim Le vicomte de Bragaleone, baseado no livro Mémoires, de Madame de La Fayette. Esta conta, sem diálogos, a história dos primeiros amores de Louis XIV, sua ruptura com Marie Mancini, seu reencontro com Louise de La Vallière, a morte de Mazarin e a desgraça de Fouquet. A narrativa é curta e sóbria, o drama está no interior dos acontecimentos e a narradora se exime de imaginar as cenas nas quais não estava presente. Dumas toma este arcabouço e, ao contrário de Madame de La Fayette, escreve cada cena indicada como uma cena teatral, com coups de théâtre, efeitos de surpresa, violência ou cômicos. Cada personagem adquire expressão - um pouco caricatural - que lhe dá vivacidade e cria a ilusão de real.*

Outro segredo da narrativa de Dumas é a importância dada às personagens secundárias. Ao introduzir na ação personagens desconhecidas que tomam parte decisiva dos acontecimentos históricos, traz a História, ao mesmo tempo, para o nível de personagens familiares e do leitor.*

Seguindo o fluxo e as necessidades internas da narrativa em busca de um efeito dramático, sacrifica a verdade cronológica e, às vezes, a verossimilhança. Aproxima acontecimentos afastados no tempo, faz seus heróis cumprirem em um ano o que só teria sido possível em dois ou três. Não se interessa em seguir fielmente os detalhes da História; interessalhe capturar o espírito, penetrar na vida quotidiana de uma época, recriando para seus leitores os acontecimentos passados e as impressões que estes causaram nas personagens que viveram realmente ou que foram criadas.

s “[...] Estaríamos errados, aliás, ao julgar uma época sob o ponto de vista de uma outra época”, “ “[...] On aurait tort au reste de juger les actions d'une époque au point de vue d'une autre époque"), diz o narrador de Les trois mousquetaires. (Dumas, Alexandre. Les trois mousquetaires et Vingt ans après. Paris: Gallimard, 1962: $401)$. Este modo de pensar é absolutamente coerente com as idéias que circulavam em sua época entre os autores de obras historiográficas (que foram o germe da consciência histórica moderna), geração que "descobriu as diferenças da cor humana através dos tempos”. Ariès, Philippe. O tempo da História. Ob. cit.: 212. 
"(Dumas citado por Schopp, Claude e Frémy, Dominique. "Quid de Dumas". Ob. cit. 1236.)
Quando escrevo um romance, ou quando escrevo um drama, suporto naturalmente as exigências do século no qual meu tema se realiza. Os lugares, os acontecimentos, me são impostos pela inexorável pontualidade da topografia, da genealogia, das datas: é preciso que a linguagem, os costumes e mesmo o porte de minhas personagens estejam em harmonia com as idéias que são correntes na época que tento retratar. Minha imaginação, às voltas com a realidade, semelhante a um homem que visita um monumento destruído, é forçada a passar por cima dos escombros, seguir os corredores, curvar-se sob as passagens secretas, para reencontrar, pouco a pouco, a planta do edifício na época em que a vida o habitava, em que a alegria o invadia de cantos e risos, em que a dor ali ficava como um eco para os soluços e para as gargalhadas.
Quand j'écris un roman, ou quand j'écris un drame, je subis tout naturellement les exigences du siècle dans lequel mon sujet s'accomplit. Les lieux, les événements, me sont imposés par l'inexorable ponctualité de la topographie, de la généalogie, des dates: il faut que le langage, le costume, l'allure même de mes personnages soient en harmonie avec les idées qu'on s'est faites de l'époque que j'essaie de peindre. Mon imagination, aux prises avec la réalité, pareille à un homme qui visite les ruines d'un monument détruit, est forcée d'enjamber par-dessus des décombres, de suivre les corridors, de se courber sous les poternes, pour retrouver ou à peu près le plan de l'édifice, à l'époque où la vie l'habitait, où la joie l'emplissait de chants et rires, où la douleur y démeurait un écho pour les sanglots et pour les rires.*

Ao trabalhar com personagens históricas, Alexandre Dumas oferece outras possibilidades para compreendê-las: oferece um outro olhar sobre a História. Sua reconstrução - no sentido a que se propõe, sem o comprometimento com a veracidade - permite ressuscitar as personagens históricas criando para o leitor uma personagem completa: expõe sentimentos e frustrações, e tira partido do anacronismo para atualizá-los.

Os romances históricos de Alexandre Dumas foram construídos com o apoio de documentos, responsáveis pelo fornecimento dos fatos e datas. Mas não lhe interessa repetir a narrativa dos acontecimentos históricos, discutir as questões que suscitam ou mesmo o sentido que os move. Interessa a Dumas ressuscitar poeticamente os seres humanos que fizeram parte desses acontecimentos. À medida que a narrativa é tecida, percebe-se que a História tem a função de fornecer 
um motivo para o romance, que o enredo histórico é complementado por outras pequenas narrativas, criando uma atmosfera que passa por uma descrição de época. Por exemplo, no início de La reine Margot, a luta política entre católicos e protestantes aparece de forma impessoal, como a narração de acontecimentos históricos; aos poucos, com o desenrolar das intrigas, já não são mais protestantes e católicos que divergem: Dumas consegue lhes dar contornos, dotando-os de um nome, caráter, emoções e sentimentos, fazendo com que essas características se sobreponham à historicidade dos fatos. Nessa medida, o leitor passa a ser levado pelo fio do romance e não pela verossimilhança da História. ${ }^{*}$

Apesar disso, no caso de um romance histórico, tanto o leitor quanto o narrador conhecem a priori o desfecho. O que mantém o interesse na narrativa é exatamente a maneira pela qual se darão os acontecimentos: a peripécia. O suspense está nas variações, não no tema, nas modalidades de revés, nas tentativas vãs, daí o paralelo que pode ser feito com a tragédia: sabemos que, mas não como, tudo vai fracassar.*

O narrador onisciente tenta, assim, tirar o máximo que pode dos pequenos acontecimentos, seguindo a lógica quase fatal que dita os romances de aventura, não deixando o leitor se esquecer de que tudo o que está sendo narrado é História, portanto mais que nunca, passado.*

Essas características empregadas por Alexandre Dumas resolvem as dificuldades que a composição apresenta a um narrador de romance histórico - isto é, a passagem do presente do leitor para o passado narrativo -, criando, ao mesmo tempo, uma cumplicidade com o leitor. Ao apresentá-lo como um narrador que passeia pelas cenas comentando o que vê, abre espaço para que este faça comentários históricos sem que isso choque, deixando sempre clara a distância temporal que o separa do acontecimento narrado; esgarçando um pouco o tecido narrativo, inserindo comentários que transportam o leitor de volta ao seu presente histórico.

Ao evitar criar uma armadilha da ilusão histórica, ao deixar que o leitor perca o referencial de sua época, Dumas coloca o narrador como uma personagem que transita entre as duas épocas, delimitando para o leitor o passado - recriado pela ficção - e o presente - tempo histórico em que o leitor
"(Dumas, Alexandre. La reine Paris: Gallimard, 1995.)

"(Tadié, Jean-Yves. Le roman 31.) 
"(Maurois, André. Les trois Dumas. Ob. cit.: 185.)
"(Michelet, Jules. Journal, t. I (1828-1848). Paris: Galli. mard, 1951.) (para quem ele escreve) e o narrador estão. Cria um mundo ficcional ligado aos fatos históricos por frágeis cordões, dando-lhes um novo sentido:

Podemos dizer dele [Dumas], não que elevou o romance à altura da História, o que não desejariam nem ele nem seus leitores, mas que ele colocou a história e o romance, encarnados em tipos inesquecíveis, em um cenário popular, diante do grande público, que é o público, e que, sob a luz de sua ribalta, história e romance viveram uma vida nova, para grande alegria das nações e dos séculos.
[...] On pourrait dire de lui $[\mathrm{Du}-$ mas], non qu'il a élevé le roman à la hauteur de l'histoire, ce que ne souhaitaient ni lui ni ses lecteurs, mais qu'il a placé l'histoire et le roman, incarnés en des types inoubliables, sur une scène populaire, devant le grand public, qui est le public, et que, sous les feux de ses projecteurs, histoire et roman ont vécu d'une vie nouvelle, pour la plus grande joie des nations et des siècles.*

Mesmo sem ser levado muito a sério por historiadores, consegue imprimir no conjunto de sua narrativa uma verdade histórica que acaba envolvendo suas cenas bem escritas. Talvez, ao debruçar-se na História, faça uma leitura absolutamente pessoal dos acontecimentos e, a partir daí, consiga retirar da época retratada a sua essência. Essa postura pode ser relacionada com uma pequena anotação de Jules Michelet em seu Journal, na qual relata sucintamente o que seria o seu método de historiografia:

Método pessoal: simplificar, biografar a História, como se fosse de um homem, como se fosse a minha. Tácito, em Roma, só viu a si mesmo, e era realmente Roma. Byron, na Suíça, só viu a si mesmo, e encontrou a verdadeira poesia da Suíça, aquela que nem mesmo ela poderia ter feito surgir.
Méthode intime: simplifier, biographer l'Histoire, comme d'un homme, comme de moi. Tacite dans Rome n'a vu que lui, et c'était vraiment Rome. Byron dans la Suisse n'a vu que lui, et il a trouvé la vraie poésie de la Suisse à laquelle elle-même n'avait pu s'élever.*

Nesse sentido, pode-se dizer que Dumas, ao fazer prevalecer a sua personalidade e seu estilo no tratamento dado à História em seus romances-folhetim, consegue torná-la acessível aos leitores, vulgarizando um tema romântico. 


\section{Maria Lúcia Dias Mendes}

Bacharel em História e mestre em Literatura Francesa pela Universidade de São Paulo. Sua dissertação de mestrado (apresentada em 2002) analisa um romance-folhetim de Alexandre Dumas, La reine Margot, e discute elementos provenientes dos gêneros contemporâneos que influenciaram a composição da obra (melodrama, drama romântico, romance de aventura e romance histórico). Prossegue suas pesquisas sobre Alexandre Dumas no doutorado na mesma instituição.

\section{Resumo}

Este artigo trata do interesse do Romantismo pela História durante o Romantismo francês. Procura delinear qual a ligação entre Alexandre Dumas e a concepção de História e de historiografia de seu tempo. Para isso, aborda Jules Michelet, um dos principais historiadores do período, por quem Dumas tinha grande admiração. Outra referência para o autor é Walter Scott, escritor escocês que desenvolve uma nova maneira de trabalhar a História na ficção e cujas inovações e técnicas foram devidamente analisadas, questionadas e superadas por Dumas. Por meio dessas referências, foi possível analisar alguns dos procedimentos utilizados por Alexandre Dumas em seus romances-folhetim, cujos enredos provêm da História da França.

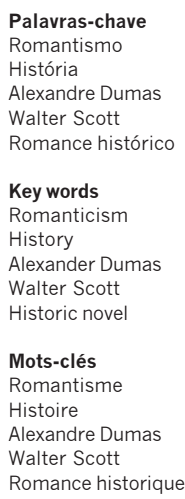

\section{Abstract}

This article analyses the interest of French Romanticism in History. It shows the links between Alexander Dumas and his conception of History and historiography. In order to do that, the article studies Jules Michelet - an outstanding historian, greatly admired by Dumas. Walter Scott is another of $\mathrm{Du}-$ mas' references from the same period. The Scotch author develops a new methodology for portraying History through fiction, that is analyzed and surpassed by Dumas. From this theoretical basis it was possible to analyze some of the techniques adopted by Dumas in his romantic feuilletons, whose plots are inspired by French History.

\section{Resumé}

Cet article commente l'intérêt du Romantisme par l'Histoire. Nous avons essayé de montrer quels sont les rapports d'Alexandre Dumas avec l'Histoire et la conception de l'Histoire et de l'historiographie de son temps (representée par Jules Michelet, très admiré par Dumas). Une autre référence pour l'auteur a été Walter Scott, un écrivain écossais qui a créé une nouvelle façon de travailler l'Histoire dans ses romans historiques. Nous avons discuté les inovations et techniques critiquées et dépassées par Dumas. À partir de cela, on a analysé les procédés utilisés par Dumas dans la composition de ses feuilletons, dont les sujets étaient fondés sur des événements de l'Histoire de France.
Recebido em 30/09/2003 Aprovado em 05/12/2003 